\title{
BMJ Open Breast feeding and the weekend effect: an observational study
}

\author{
Emla Fitzsimons, ${ }^{1,2}$ Marcos Vera-Hernández ${ }^{2,3}$
}

To cite: Fitzsimons E, VeraHernández M. Breast feeding and the weekend effect: an observational study. BMJ Open 2016;6:e010016. doi:10.1136/bmjopen-2015010016

- Prepublication history for this paper is available online. To view these files please visit the journal online (http://dx.doi.org/10.1136/ bmjopen-2015-010016).

Received 17 September 2015 Revised 17 May 2016 Accepted 18 May 2016
CrossMark

\footnotetext{
${ }^{1} \mathrm{UCL}$ Institute of Education, London, UK

${ }^{2}$ Institute for Fiscal Studies, London, UK

${ }^{3}$ Department of Economics, University College London, London, UK
}

Correspondence to Professor Emla Fitzsimons; e.fitzsimons@ucl.ac.uk

\section{ABSTRACT}

Objective: To compare the incidence of breast feeding by day of week of birth.

Design: Retrospective database study using 16508 records from the 2005 and 2010 Infant Feeding Surveys.

Setting: England and Wales, UK.

Participants: Mothers of a sample of births from among all registered births in the periods AugustSeptember 2005 and August-October 2010.

Main outcome measure: Incidence of breast feeding after birth.

Results: Among babies of mothers who left full-time education aged 16 or under, the incidence of breast feeding was 6.7 percentage points lower $(95 \% \mathrm{Cl} 1.4$ to 12.1 percentage points) for those born on Saturdays than for those born on Mondays-Thursdays. No such differences by day of week of birth were observed among babies of mothers who left school aged 17 or over.

Conclusions: Breastfeeding policy should take into account differences in breast feeding by day of week of birth, which are apparent among low-educated mothers. Further research is needed to ascertain the reason for this finding.

\section{INTRODUCTION}

An extensive literature documents the potential benefits of breast feeding for infant health. ${ }^{1-10}$ These benefits might extend to the long term. ${ }^{11}$ Breast feeding is associated with lower blood pressure and lower risk of type 2 diabetes and obesity, as well as with higher cognitive development measures. ${ }^{7}{ }^{12-21}$ Alongside this, there is a strong socioeconomic pattern in breast feeding. In the UK in 2010, the incidence of breast feeding was $91 \%$ among babies whose mothers left full-time education when they were over 18, compared with $75 \%$ among those whose mothers left full-time education aged 17 or 18 and $63 \%$ among those whose mothers were 16 or under when they left full-time education. ${ }^{22}$

Weekend excess mortality is well documented for emergency admissions, including stroke, trauma, kidney and cardiovascular emergencies. ${ }^{23-30}$ Although such a 'weekend effect' might be due to differences in case

\section{Strengths and limitations of this study}

- We use data from the 2005 and 2010 Infant Feeding Surveys, the most recent ones available.

- Statistical significance is adjusted using Bonferroni corrections.

- Breastfeeding incidence is self-reported and hence subject to recall bias, although questionnaires were sent to mothers when their children were aged $\sim 6$ weeks.

- Response rates to the Infant Feeding Survey in England and Wales were $61.8 \%$ in 2005 and $52.5 \%$ in 2010 , although weights provided by the survey adjust for non-response.

- Day of week of birth is missing for 1469 children in the 2010 Infant Feeding Survey.

mix between weekend and weekday admissions, most studies suspect it is due to the decreased availability of experienced healthcare professionals on weekends. Some mothers benefit from the support of hospital staff to initiate and successfully establish breast feeding. ${ }^{31-44}$ We conducted a retrospective study of breast feeding in the years 2005 and 2010, comparing breast feeding incidence rates by day of week of birth. We postulated that breast feeding may vary by day of week of birth, especially for the babies of the least educated mothers, who are less likely to have access to other sources of support and information not provided at hospital.

\section{METHODS}

Data

This paper uses the 2005 and 2010 Infant Feeding Surveys (IFS 2005, 2010). ${ }^{22} 45$ The IFS is a national survey of infant feeding practices carried out every 5 years since 1975 and the main source used to record breast feeding statistics. We attempted to access day of week of birth for 2000, but these data were not available. The IFS contains, among other things, information on the prenatal period (check-ups, classes, intentions on feeding methods, smoking, drinking and 
nutritional supplement intake), birth experience and the early postnatal period (delivery method, details on breast milk and infant formula milk intake and how the latter is prepared, and support at home), health during the early weeks, introduction of solid foods, intake of additional drinks and supplementary vitamins and basic sociodemographics.

For each country of the UK, unclustered samples of births were drawn from birth registration records containing births that occurred in the periods AugustSeptember for the 2005 survey and August-October for the 2010 survey. The surveys were administered via post using a paper questionnaire. Mothers whose children were included in the sample were sent by post an introductory letter, questionnaire and reply-paid envelope, followed by a reminder letter a week later. Up to two more mailings were sent to those mothers who did not reply. The dispatch of the initial questionnaire was staggered on a weekly basis to ensure it reached the mother when the baby was aged $\sim 4-10$ weeks for the 2005 survey and 6 weeks for the 2010 survey. In 2010, there was also the option, for the first time, to fill out the questionnaire online. In each survey, three stages of data collection were conducted, with stage 1 carried out when babies were aged $\sim 4-10$ weeks, stage 2 when they were aged $\sim 4-6$ months and stage 3 when they were aged 8-10 months. This paper uses data from stage 1 to measure the incidence of breast feeding.

This analysis uses data from the 2005 and 2010 surveys for England and Wales, which sampled 13287 births in 2005 and 18990 in 2010. Of those sampled, 8210 and 9969 completed the stage 1 questionnaire in 2005 and 2010, respectively, yielding response rates of $61.8 \%$ and $52.5 \%$, respectively. The total numbers of births for England and Wales were 645835 in 2005 and 723165 in $2010 .{ }^{46} 47$

The variable 'day of week of birth' was obtained on request from TNS BMRB (for 2005) and IFF Research (for 2010).

\section{Statistical analysis}

The primary outcome of interest is the incidence of breast feeding after birth. The incidence measures the percentage of babies who were breast fed initially, including all babies who were put to the breast at all, even if only once. It also includes babies who were given expressed breast milk. As in the official survey reports, the incidence of breast feeding is measured from the first stage of each survey. ${ }^{22} 45$

We excluded from the analysis 1469 babies whose day of week of birth was not available in the 2010 survey, 170 whose mother's education status was not reported, 24 whose mother's age was not known and 8 whose breastfeeding status was not known. The final sample size is 16508 .

Using weighted logistic regression, we examined the relationship between day of week of birth and our primary outcome (ever breast fed). Proportions were obtained using the estimated parameters averaged across the sample. The breast feeding variable takes the value 0 if the mother reports that the 'baby has never been given breast milk or been put to breast' and 1 otherwise. The analysis pools the 2005 and 2010 data sets. Weighted logistic regression controls for the year of survey (2005 vs 2010), type of delivery (normal vs other), maternal age in categories (under 20, 20-24, 25-29, 30-34, 35 or over), country (Wales vs England) and ethnicity (white vs other). Statistical analysis was conducted using Stata software, V.13.1 (StataCorp. Stata Statistical Software: Release 13. College Station, Texas: StataCorp LP, 2013). Proportions, 95\% CIs and p values were obtained using the Stata margins command.

Given the stark differences in breast feeding incidence by maternal education, we hypothesised that the effect of day of week of birth on breast feeding might vary by education status. We investigated this hypothesis by entering an interaction term between day of week of birth and education. The interaction term was statistically significant at the $5 \%$ level $(\mathrm{p}=0.027)$. The subsequent analysis split the data by education status, where low education includes those who left full-time education aged 16 or under and high education includes those who left fulltime education aged 17 or over. Although education is not a direct measure of health literacy, it is a proxy for it and is also positively associated with the mother's ability to access different sources of breast feeding support.

To explore the robustness of the findings, additional logistic regression models were estimated with an expanded set of covariates: a binary variable indicating whether the mother was married/cohabiting, prenatal feeding intention (binary variables for exclusive breast feeding and any breast feeding), prenatal care that included infant feeding discussions (binary variables for check-ups and attendance at prenatal classes), a binary variable indicating whether the mother was informed of the health benefits of breast feeding, binary variables as to whether the baby was in special care and whether the baby was put under a lamp for jaundice, and the baby's length of stay in hospital in hours.

\section{RESULTS}

The rate of incidence of breast feeding among mothers with low education is $62.7 \%$, compared with $85.2 \%$ among those with high education.

Table 1 shows maternal characteristics by the baby's day of week of birth. It highlights that the distributions of age, age left full-time education, ethnicity, type of delivery and length of hospital stay are similar across days of week of birth. Figures 1 and 2 show the lengths of the baby's hospital stay across days of week of birth for low-educated and high-educated mothers, respectively. The observed pattern likely reflects the facts that babies tend to be born at night and discharged during the day and that hospital discharge policy does not vary by the day of the week. The Kruskal-Wallis rank test does not reject the hypothesis that the distribution of length of stay is the same across days of week of birth ( $p$ values 


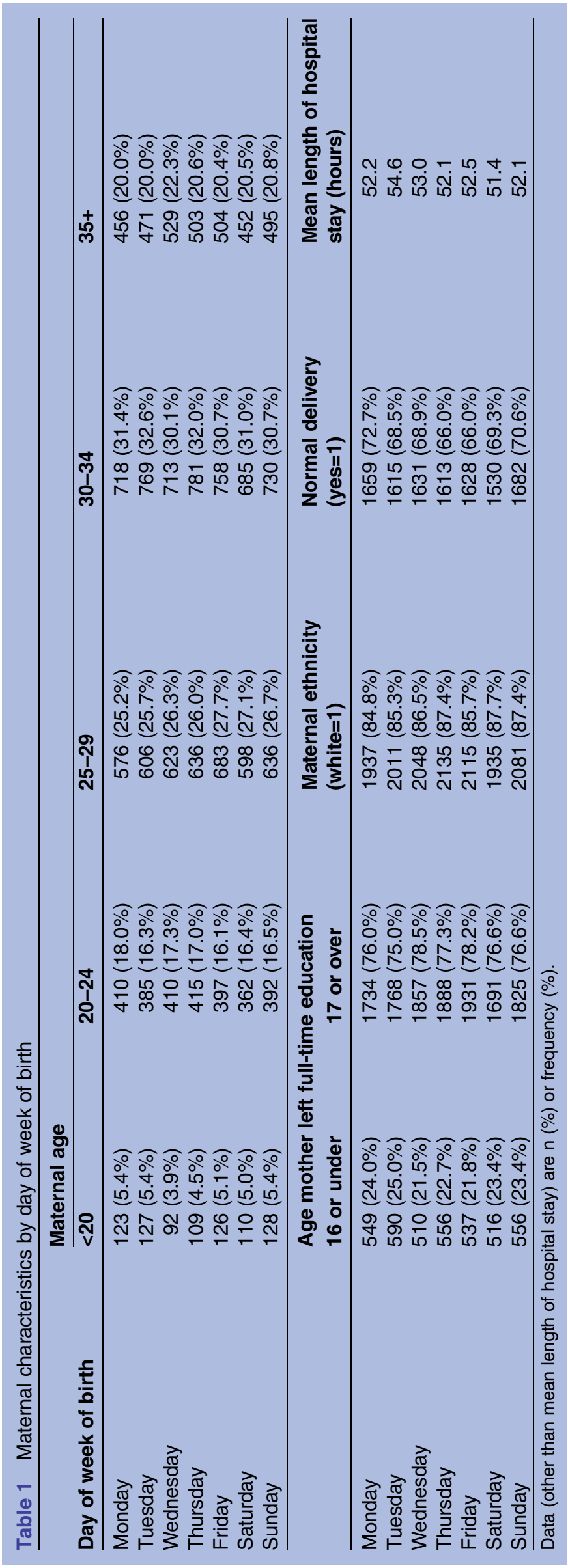

are 0.173 and 0.159 for low-educated and high-educated mothers, respectively).

Table 2 shows the incidence of breast feeding by day of week of birth and maternal education status. The incidence of breast feeding is very similar across the days of week of birth for the high educated. However, for the low educated, there is a dip in breast feeding for babies born on Friday and Saturday. Table 3 explores this relationship using logistic regression.

Table 3 shows unadjusted and adjusted differences in the weighted percentages of breastfed babies born on any of Friday, Saturday or Sunday with respect to those born on Monday-Thursday, obtained using a logistic regression with incidence of breast feeding as the dependent variable, stratified by education status. The regression compares separately the births taking place on Friday, Saturday and Sunday with the births occurring on Monday-Thursday inclusive. For the high educated, the differences in weighted proportions are very close to zero and not statistically different from zero in any case. For the low educated, on the other hand, the adjusted (unadjusted) breast feeding incidence is 6.7 percentage points (6.6 percentage points) lower for babies born on Saturdays versus those born on Mondays-Thursdays, with the $\mathrm{p}=0.014$ (0.019), which falls below (slightly above) the Bonferroni-adjusted significance level of 0.0167 .

We find that $63.7 \%$ of babies of low-educated mothers who were born on Monday-Thursday initiate breast feeding, compared with $57.1 \%$ of babies born on Saturday. Put differently, for babies of low-educated mothers, being born on Saturday rather than MondayThursday decreases their probability of initiating breast feeding by $10.3 \%$.

Using the same survey data, we estimate that $23.44 \%$ of births are to low-educated mothers and that $13.05 \%$ of births occur on Saturdays. Multiplying these percentages by the absolute difference of 6.7 percentage points and the total number of births in England and Wales in 2010 (723 165), we calculate that 1482 babies a year are not breast fed in England and Wales because they were born on Saturday rather than on Monday-Thursday.

Results of the logistic regressions estimated using an expanded set of covariates are similar to the main results reported in table 3: the difference in the weighted breast feeding incidence for Saturday versus Monday-Thursday is -4.7 percentage points $(95 \%$ CI -8.3 to -1.0 percentage points, $\mathrm{p}=0.012$ ) for loweducated mothers and -0.4 percentage points $(95 \%$ CI -2.0 to 1.1 percentage points, $\mathrm{p}=0.576$ ) for higheducated mothers. However, the sample sizes were lower (3487 for low-educated mothers and 11606 for high-educated mothers) due to missing values in the additional covariates included.

\section{DISCUSSION}

We find that for babies of low-educated mothers, being born on Saturday rather than Monday-Thursday 


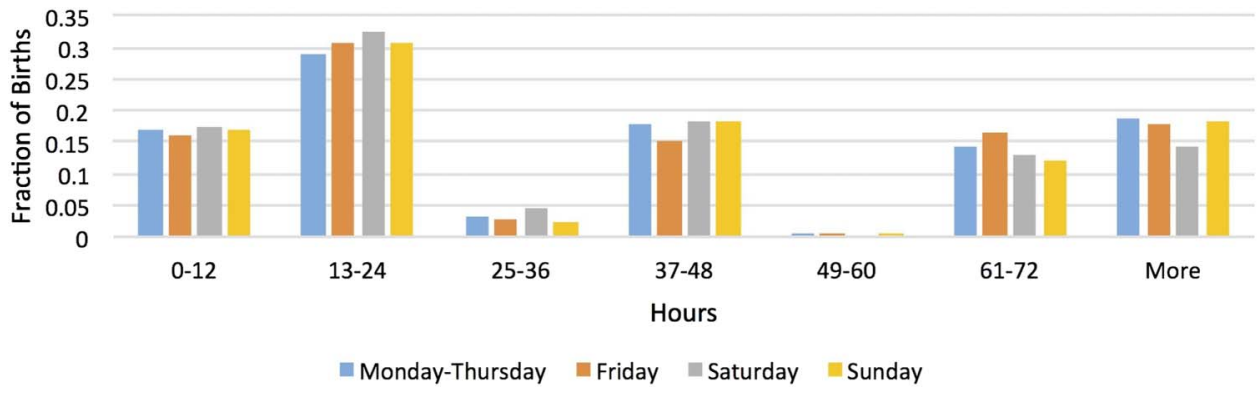

Figure 1 Distribution of length of stay by day of birth for low-educated mothers. Source: 2005 and 2010 Infant Feeding Surveys.

decreases their probability of being breast fed by $10.3 \%$. To put this figure in context, it is equivalent to 1482 fewer babies being breast fed per year; it is also comparable with the effect of the Unicef Baby-Friendly Initiative, a breast feeding-focused intervention that increased the probability of initiating breast feeding by $10 \% .^{33}$

Our study has several limitations. We do not have control over statistical power as sample sizes are dictated by the IFS. We use data from the 2005 and 2010 surveys, the most recent ones available. Response rates to the IFS were $61.8 \%$ in 2005 and $52.5 \%$ in 2010, although weights provided by the survey adjust for non-response. Breastfeeding incidence is self-reported and hence subject to recall bias, although questionnaires were sent to mothers when their children were aged $\sim 6$ weeks.

Data on the day of week of birth were missing for 1469 children in the 2010 IFS. However, the percentage of missing records for women with high education is very similar to that for women with low education $(14.5 \%$ vs $15.2 \%)$. Table 4 reports on the statistical association between records with missing day of week of birth and other variables, stratified by education. Using Pearson's $\chi^{2}$ test, no statistically significant associations were found for low-educated mothers. Among mothers with high education, white mothers have a smaller frequency of having missing data. Hence, our results for higheducated mothers should be interpreted with extra caution.

Another limitation of our study is that our data do not contain time of birth. This blurs the effect of the day of week of birth because children born later on Saturday are more likely to still be in hospital on Monday compared with children born early on Saturday, yet this study treats them the same way. We hypothesise that had we had access to data on time of birth, the day of week of birth effect would be larger.

Other studies report a weekend effect on outcomes such as mortality. ${ }^{23-30}$ Although no conclusive reasons behind these differences are reported, most studies suggest that they may be due to lower staffing and service levels at weekends, as well as differences in the case mix of patients at different times of the week. Facing staff constraints at weekends, hospitals may prioritise labour and delivery, to the detriment of breast feeding support in postnatal wards. Extensive research has shown that early support for infant feeding is critical to the initiation and establishment of successful breast feeding. ${ }^{31-44}$ Other reasons for our findings cannot be ruled out. For instance, visits to hospital from relatives may be higher for children born on Saturdays, which might distract from breast feeding counselling.

Friday is the day with the second lowest breast feeding incidence among low-educated mothers. Children born early on Fridays might benefit from breast feeding support services available during weekdays, which would attenuate the weekend effect for those born late on Fridays. Thus, even though the difference in breast feeding incidence between children born on Fridays and children born on Monday-Thursday did not reach statistical significance, it might still be important to make sure that they receive full breast feeding support.

An effect was not found on Sundays. This might be because, given a median hospital stay of 48 hours,
Figure 2 Distribution of length of stay by day of birth for high-educated mothers. Source: 2005 and 2010 Infant Feeding Surveys.

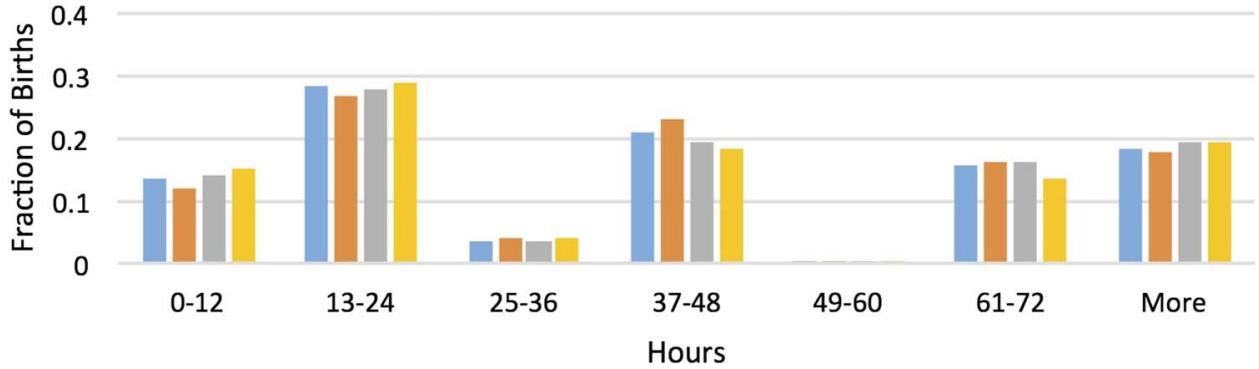

Monday-Thursday $\square$ Friday $\square$ Saturday Sunday 
mothers are more likely to be in hospital on weekdays (in particular Monday and Tuesday), thereby benefitting from breast feeding counselling available on weekdays. In the sample, there are 556 Sunday births to loweducated mothers in England and Wales. Of these, only 136 babies stayed <24 hours in hospital; hence, the majority of children $(420(=556-136)$ out of 556) born on Sunday were still in hospital on Monday. Moreover,

Table 2 Incidence of breast feeding by day of week of birth and maternal education status

\begin{tabular}{lllll}
\hline $\begin{array}{l}\text { Day of week } \\
\text { of birth }\end{array}$ & \multicolumn{2}{l}{$\begin{array}{l}\text { Low educated } \\
\text { (n=3814) }\end{array}$} & \multicolumn{2}{l}{$\begin{array}{l}\text { High educated } \\
(\mathbf{n = 1 2} \text { 694) }\end{array}$} \\
\hline Monday & 549 & $(61.8 \%)$ & 1734 & $(86.0 \%)$ \\
Tuesday & 590 & $(63.2 \%)$ & 1768 & $(86.0 \%)$ \\
Wednesday & 510 & $(64.8 \%)$ & 1857 & $(85.6 \%)$ \\
Thursday & 556 & $(64.9 \%)$ & 1888 & $(83.2 \%)$ \\
Friday & 537 & $(59.5 \%)$ & 1931 & $(85.7 \%)$ \\
Saturday & 516 & $(57.1 \%)$ & 1691 & $(85.0 \%)$ \\
Sunday & 556 & $(67.5 \%)$ & 1825 & $(84.9 \%)$ \\
\hline
\end{tabular}

Data are $n(\%)$. Weighted. 'Low educated' includes those who left education aged 16 or under. 'High educated' includes those who left education aged 17 or over. depending on the exact time of birth, some of the 136 babies who stayed $<24$ hours were not discharged until Monday. Ultimately, there are few babies born on Sundays who are not also in hospital on Monday, which may be the reason that an effect on Sunday was not found.

An effect was not found for mothers with high education levels. They may be more effective at accessing whatever hospital support is available as well as alternative sources of support such as helplines, community services, information leaflets and lactation consultants. They may also be more likely to use antenatal services better and therefore have more information before the delivery. ${ }^{48}$

These findings have important policy implications. Much of the existing literature documenting a weekend effect is focused on mortality. This paper shows that other dimensions of hospital care are also likely to be affected. Moreover, breast feeding can have long-term benefits for health and cognition, and it can bring future savings to the healthcare system. Current policy to promote breast feeding in the UK should take account of these disparities by day of week of birth, especially for low-educated mothers. Subsequent research should investigate whether these disparities are caused by

Table 3 Logistic regression: relationship between day of week of birth and whether mother ever breast fed

\begin{tabular}{|c|c|c|c|c|}
\hline \multirow[b]{2}{*}{ Day of week of birth } & \multicolumn{2}{|l|}{ Unadjusted } & \multicolumn{2}{|l|}{ Adjusted } \\
\hline & $\begin{array}{l}\text { Low } \\
\text { educated }\end{array}$ & $\begin{array}{l}\text { High } \\
\text { educated }\end{array}$ & $\begin{array}{l}\text { Low } \\
\text { educated }\end{array}$ & $\begin{array}{l}\text { High } \\
\text { educated }\end{array}$ \\
\hline \multicolumn{5}{|l|}{ Friday } \\
\hline $\begin{array}{l}\text { Difference in percentage breast fed } \\
\text { (Friday vs Monday-Thursday) }\end{array}$ & 4.2 ppt. & 0.5 ppt. & -3.2 ppt. & 0.4 ppt. \\
\hline $95 \% \mathrm{Cl}$ of difference & $(-9.7$ to 1.3$)$ & $(-1.6$ to 2.6$)$ & $(-8.4$ to 2.1$)$ & $(-1.6$ to 2.4$)$ \\
\hline $\mathrm{p}$ Value & 0.134 & 0.639 & 0.233 & 0.688 \\
\hline OR & 0.837 & 1.041 & 0.866 & 1.036 \\
\hline $95 \% \mathrm{Cl}$ of $\mathrm{OR}$ & (0.666 to 1.053$)$ & (0.879 to 1.233$)$ & (0.684 to 1.095$)$ & (0.871 to 1.233$)$ \\
\hline \multicolumn{5}{|l|}{ Saturday } \\
\hline $\begin{array}{l}\text { Difference in percentage breast fed } \\
\text { (Saturday vs Monday-Thursday) }\end{array}$ & -6.6 ppt.* & $-0.2 \mathrm{ppt}$ & -6.7 ppt.** & 0.3 ppt. \\
\hline $95 \% \mathrm{Cl}$ of difference & $(-12.1$ to -1.1$)$ & $(-2.4$ to 2.1$)$ & $(-12.1$ to -1.4$)$ & $(-1.9$ to 2.4$)$ \\
\hline $\mathrm{p}$ Value & 0.019 & 0.877 & 0.014 & 0.805 \\
\hline OR & 0.759 & 0.986 & 0.742 & 1.023 \\
\hline $95 \% \mathrm{Cl}$ of $\mathrm{OR}$ & (0.605 to 0.953$)$ & $(0.827$ to 1.176$)$ & (0.587 to 0.938$)$ & (0.854 to 1.225$)$ \\
\hline \multicolumn{5}{|l|}{ Sunday } \\
\hline $\begin{array}{l}\text { Difference in percentage breast fed } \\
\text { (Sunday vs Monday-Thursday) }\end{array}$ & 3.9 ppt. & -0.3 ppt. & $3.8 \mathrm{ppt}$ & 0.1 ppt. \\
\hline $95 \% \mathrm{Cl}$ of difference & $(-1.2$ to 8.9$)$ & $(-2.4$ to 1.9$)$ & $(-1.1$ to 8.9$)$ & $(-2.0$ to 2.1$)$ \\
\hline p Value & 0.136 & 0.788 & 0.131 & 0.940 \\
\hline OR & 1.187 & 0.977 & 1.197 & 1.007 \\
\hline $95 \% \mathrm{Cl}$ of $\mathrm{OR}$ & (0.944 to 1.493$)$ & (0.824 to 1.158$)$ & (0.944 to 1.516$)$ & (0.846 to 1.198$)$ \\
\hline Observations & 3814 & 12694 & 3814 & 12694 \\
\hline \multicolumn{5}{|c|}{$\begin{array}{l}\text { Data from } 2005 \text { and } 2010 \text { pooled. All statistical inferences control for year of survey, type of delivery (normal vs other), maternal age in } \\
\text { categories (under } 20,20-24,25-29,30-34,35 \text { or over), country (Wales vs England) and ethnicity (white vs other). Effects are relative to } \\
\text { Monday-Thursday (reference). 'Low educated' includes those who left education aged } 16 \text { or under. 'High educated' includes those who left } \\
\text { education aged } 17 \text { or over. The table reports the weighted percentage of breastfed babies born on any of Friday, Saturday or Sunday } \\
\text { (separate rows) minus the weighted percentage of breastfed babies born on Monday-Thursday, its } 95 \% \mathrm{Cl}, \mathrm{p} \text { value, OR and the } 95 \% \mathrm{Cl} \text { of } \\
\text { the OR. Significance levels include Bonferroni corrections. } \\
{ }^{*} \mathrm{p}<0.1 / 3=0.0333 ;{ }^{* \star} p<0.05 / 3=0.0167 \text {. } \\
\text { ppt., percentage points. }\end{array}$} \\
\hline
\end{tabular}


Table 4 Percentage of records with missing day of week of birth in the 2010 Infant Feeding Survey

\begin{tabular}{llll}
\hline Variables & Low educated (\%) & p Value & High educated (\%) \\
\hline Normal delivery & 15.3 & 0.81 & 14.2 \\
Caesarean delivery & 14.9 & & 14.8 \\
White & 15.3 & 0.53 & 13.6 \\
Non-white & 14.9 & & 18.8 \\
Maternal age <20 & 11.3 & 0.57 & 18.4 \\
Maternal age 20-24 & 14.9 & & 16.4 \\
Maternal age 25-29 & 14.5 & & 14.4 \\
Maternal age 30-34 & 16.5 & & 13.5 \\
Maternal age 35+ & 16.7 & 14.3 & 0.08 \\
\hline
\end{tabular}

$\mathrm{p}$ Value refers to Pearson's $\chi^{2}$ test.

differences in staffing across the week and/or differences in the number or composition of visits paid by friends and relatives.

An important finding is that the day of week of birth only matters for breast feeding for those from less educated backgrounds. Given long-term beneficial effects of breast feeding, this finding suggests that the day of week of birth may play some role in widening disparities in outcomes across socioeconomic groups.

The research showcases the importance of the IFS in monitoring breast feeding and providing important new evidence for policy. Given that the ninth IFS, due in 2015, did not take place, alternative data sources will be required to monitor progress on the findings we report here.

\section{CONCLUSIONS}

Among mothers who left full-time education aged 16 or under, the incidence of breast feeding was 6.7 percentage points lower among babies born on Saturdays than among those born on Mondays-Thursdays. No such discrepancies were observed among mothers who were older when they left full-time education. In the absence of a prospective study, further research is needed to ascertain the exact reasons for this finding.

Acknowledgements The authors thank Professor Mary J Renfrew at the University of Dundee, Lydia Fellows at IFF Research and Rebecca Hamlyn at TNS BMRB for their assistance with data acquisition.

Contributors Both authors were responsible for the study design, data analysis and interpretation of the results. EF wrote the first draft of the Methods and Results sections, while MV-H wrote the first draft of the Introduction and Discussion sections. As such, the authors are listed in alphabetical order. All errors are the responsibility of the authors. The corresponding author had full access to all the data in the study and had final responsibility for the decision to submit for publication. EF is the guarantor.

Funding This work was supported by the Economic and Social Research Council via the ESRC-funded Centre for the Microeconomic Analysis of Public Policy (CPP) at the Institute for Fiscal Studies, grant reference ES/H021221/1.

Competing interests None declared.

Provenance and peer review Not commissioned; externally peer reviewed.

Data sharing statement The statistical codes are available from the corresponding author.

Open Access This is an Open Access article distributed in accordance with the terms of the Creative Commons Attribution (CC BY 4.0) license, which permits others to distribute, remix, adapt and build upon this work, for commercial use, provided the original work is properly cited. See: http:// creativecommons.org/licenses/by/4.0/

\section{REFERENCES}

1. Howie PW, Forsyth JS, Ogston SA, et al. Protective effect of breast feeding against infection. BMJ 1990;300:11-16.

2. Pisacane A, Graziano L, Mazzarella G, et al. Breast-feeding and urinary tract infection. J Pediatr 1992;120:87-9.

3. Kramer MS, Chalmers B, Hodnett ED, et al, PROBIT Study Group (Promotion of Breastfeeding Intervention Trial). Promotion of Breastfeeding Intervention Trial (PROBIT): a randomized trial in the Republic of Belarus. JAMA 2001;285:413-20.

4. Dyson L, Renfrew MJ, McFadden A, et al. Promotion of breastfeeding initiation and duration. Evidence into practice briefing. London, UK: National Institute for Health and Clinical Excellence, 2006.

5. Quigley MA, Cumberland $\mathrm{P}$, Cowden JM, et al. How protective is breast feeding against diarrhoeal disease in infants in 1990s England? A case-control study. Arch Dis Child 2006;91:245-50.

6. Quigley MA, Kelly YJ, Sacker A. Breastfeeding and hospitalization for diarrheal and respiratory infection in the United Kingdom Millennium Cohort Study. Pediatrics 2007;119:e837-42.

7. Ip S, Chung M, Raman G, et al. Breastfeeding and Maternal and Infant Health Outcomes in Developed Countries. Evidence Report/ Technology Assessment 153. Rockville, MD: Agency for Healthcare Research and Quality, 2007.

8. Quigley MA, Kelly YJ, Sacker A. Infant feeding, solid foods and hospitalisation in the first 8 months after birth. Arch Dis Child 2009;94:148-50.

9. Fisk CM, Crozier SR, Inskip HM, et al. Breastfeeding and reported morbidity during infancy: findings from the Southampton Women's Survey. Matern Child Nutr 2011;7:61-70.

10. Renfrew MJ, Pokhrel S, Quigley M, et al. Preventing disease and saving resources: the potential contribution of increasing breastfeeding rates in the UK. London, UK: UNICEF UK, 2012. http://www.unicef.org.uk/Documents/Baby Friendly/Research/ Preventing_disease_saving_resources.pdf?epslanguage $=$ en (accessed June 2015).

11. Lucas A. Programming by early nutrition in man. Ciba Found Symp 1991;156:38-50; discussion 50-5.

12. Anderson JW, Johnstone BM, Remley DT. Breast-feeding and cognitive development: a meta-analysis. Am J Clin Nutr 1999;70:525-35.

13. Arenz S, Rückerl R, Koletzko $B$, et al. Breast-feeding and childhood obesity - a systematic review. Int J Obes 2004;28:1247-56.

14. Harder T, Bergmann R, Kallischnigg G, et al. Duration of breastfeeding and risk of overweight: a meta-analysis. $\mathrm{Am} \mathrm{J}$ Epidemiol 2005;162:397-403.

15. Kramer MS, Fombonne E, Igumnov S, et al. Effects of prolonged and exclusive breastfeeding on child behavior and maternal adjustment: evidence from a large, randomized trial. Pediatrics 2008;121:e435-40.

16. Chivers $\mathrm{P}$, Hands $\mathrm{B}$, Parker $\mathrm{H}$, et al. Body mass index, adiposity rebound and early feeding in a longitudinal cohort (Raine Study). Int J Obes(Lond) 2010;34:1169-76.

17. Borra C, lacovou M, Sevilla A. The effect of breastfeeding on children's cognitive and noncognitive development. Labour Econ 2012;19:496-515. 
18. Del Bono E, Rabe B. Breastfeeding and child cognitive outcomes: evidence from a hospital-based breastfeeding support policy. Institute for Social and Economic Research Working Paper 2012-29. 2012. https://www.iser.essex.ac.uk/research/publications/workingpapers/iser/2012-29.pdf (accessed Jan 2014).

19. Quigley MA, Hockley C, Carson C, et al. Breastfeeding is associated with improved child cognitive development: a population-based cohort study. J Pediatr 2012;160:25-32.

20. Fitzsimons E, Vera-Hernández M. Food for thought? Breastfeeding and child development. Institute for Fiscal Studies Working Paper 13/31. 2013. http://www.ifs.org.uk/wps/wp201331.pdf (accessed Jun 2015).

21. Horta BL, Victora CG. Long-term effects of breastfeeding: a systematic review. Geneva, Switzerland: WHO, 2013.

22. McAndrew F, Thompson J, Fellows L, et al. Infant feeding survey 2010. London, UK: Health and Social Care Information Centre, 2012. http://www.hscic.gov.uk/catalogue/PUB08694 (accessed June 2015).

23. Bell CM, Redelmeier DA. Mortality among patients admitted to hospitals on weekends as compared with weekdays. N Engl J Med 2001;345:663-8.

24. Kostis WJ, Demissie K, Marcella SW, et al. Weekend versus weekday admission and mortality from myocardial infarction. $N$ Engl J Med 2007;356:1099-109.

25. Horwich TB, Hernandez AF, Liang L, et al. Weekend hospital admission and discharge for heart failure: association with quality of care and clinical outcomes. Am Heart J 2009;158:451-8.

26. Aylin P, Yunus A, Bottle A, et al. Weekend mortality for emergency admissions. A large, multicentre study. Qual Saf Health Care 2010;19:213-17.

27. Fang J, Saposnik G, Silver FL, et al. Association between weekend hospital presentation and stroke fatality. Neurology 2010;75:1589-96.

28. James MT, Wald R, Bell CM, et al. Weekend hospital admission, acute kidney injury, and mortality. J Am Soc Nephrol 2010;21:845-51.

29. Gallerani M, Imberti D, Bossone E, et al. Higher mortality in patients hospitalized for acute aortic rupture or dissection during weekends. $J$ Vasc Surg 2012;55:1247-54.

30. Schneider EB, Hirani SA, Hambridge HL, et al. Beating the weekend trend: increased mortality in older adult traumatic brain injury (TBI) patients admitted on weekends. J Surg Res 2012;177:295-300.

31. Cattaneo A, Buzzetti R. Effect on rates of breast feeding of training for the Baby Friendly Hospital Initiative. BMJ 2001;323: 1358-62.

32. Merten S, Dratva J, Ackermann-Liebrich U. Do Baby-Friendly Hospitals influence breastfeeding duration on a national level? Pediatrics 2005;116:e702-8.
33. Bartington S, Griffiths LJ, Tate AR, et al. Are breastfeeding rates higher among mothers delivering in Baby Friendly accredited maternity units in the UK? Int J Epidemiol 2006;35:1178-86.

34. DiGirolamo AM, Grummer-Strawn LM, Fein SB. Effect of maternity-care practices on breastfeeding. Pediatrics 2008;122 (Suppl 2):S43-9.

35. National Institute for Health and Clinical Excellence. Improving the nutrition of pregnant and breastfeeding mothers and children in low-income households. London, UK: NICE, 2008.

36. Spiby $\mathrm{H}, \mathrm{McC}$ ormick $\mathrm{F}$, Wallace $\mathrm{L}$, et al. A systematic review of education and evidence-based practice interventions with health professionals and breast feeding counsellors on duration of breast feeding. Midwifery 2009;25:50-61.

37. Dyson L, Renfrew MJ, McFadden A, et al. Policy and public health recommendations to promote the initiation and duration of breast-feeding in developed country settings. Public Health Nutr 2010;13:137-44.

38. Renfrew MJ, McCormick FM, Wade A, et al. Support for healthy breastfeeding mothers with healthy term babies. Cochrane Database Syst Rev 2012;(5):CD001141.

39. Entwistle F. The evidence and rationale for the UNICEF UK Baby Friendly Initiative standards. London, UK: UNICEF UK, 2013.

40. Hallowell SG, Spatz DL, Hanlon AL, et al. Characteristics of the NICU work environment associated with breastfeeding support. Adv Neonatal Care 2014;14:290-300.

41. Fugate K, Hernandez I, Ashmeade T, et al. Improving human milk and breastfeeding practices in the NICU. J Obstet Gynecol Neonatal Nurs 2015;44:426-38; quiz E14-5.

42. Spatz DL, Froh EB, Schwarz J, et al. Pump early, pump often: a continuous quality improvement project. $J$ Perinat Educ 2015;24:160-70.

43. Dias de Oliveira L, Justo Giugliani ER, Córdova do Espírito Santo L, et al. Counselling sessions increased duration of exclusive breastfeeding: a randomized clinical trial with adolescent mothers and grandmothers. Nutr J 2014;13:73.

44. Rozga MR, Kerver JM, Olson BH. Impact of peer counselling breast-feeding support programme protocols on any and exclusive breast-feeding discontinuation in low-income women. Public Health Nutr 2015;18:453-63.

45. Bolling K, Grant C, Hamlyn B. Infant feeding survey 2005. London, UK: Health and Social Care Information Centre, 2007.

46. ONS. Birth statistics: births and patterns of family building in England and Wales (FM1). London, UK: Office for National Statistics, 2008.

47. ONS. Births and deaths in England and Wales, 2010. London, UK: Office for National Statistics, 2011.

48. Feijen-de Jong El, Jansen DE, Baarveld F, et al. Determinants of late and/or inadequate use of prenatal healthcare in high-income countries: a systematic review. Eur J Public Health 2012;22:904-13. 